\title{
Agronomic characteristics associated with the normalized difference vegetation index (NDVI) in the peanut crop
}

\author{
Cristiano Zerbato $^{1 *}$, David Luciano Rosalen ${ }^{1}$, Carlos Eduardo Angeli Furlani ${ }^{1}$, Juliano Deghaid ${ }^{1}$, \\ Murilo Aparecido Voltarelli ${ }^{2}$
}

\author{
${ }^{1}$ UNESP - Univ Estadual Paulista, Campus de Jaboticabal, SP, Department Agricultural Engineering, Via de \\ Acesso Prof. Paulo Donato Castellane, s/n, 14884-900, São Paulo, Brazil \\ ${ }^{2}$ Universidade Federal de Viçosa, Campus Viçosa, MG, Department Agricultural Engineering, Avenida Peter \\ Henry Rolfs, s/n - 36570-900, Minas Gerais, Brazil
}

*Corresponding author: cristianozerbato@hotmail.com

\begin{abstract}
Advances in agricultural technology have led to the development of active remote sensing equipment that can potentially estimate components of crop production; however, this assessment is still in its early stages for the peanut crop. The objective of this study was to evaluate the normalized difference vegetation index (NDVI) generated by a terrestrial sensor and its relationship with agronomic variables of peanut crops grown at different densities. The parameters evaluated were the NDVI, pod yield, mass of 100 grains, green and dry mass and vegetation cover. The study was conducted in an experimental field and used a randomized block design with plots consisting of four plant populations $\left(86,111,103,520,127,603\right.$ and 141,144 plants ha $\left.{ }^{-1}\right)$ with six replicates per treatment. The two densest populations of peanut plants showed similar behavior among the variables analyzed, whereas the variables of vegetation cover, yield and plant population strongly correlated with the NDVI obtained by the terrestrial sensor. For the seeding rates, the higher densities $\left(14\right.$ and 18 seeds $\left.\mathrm{m}^{-1}\right)$ are the most recommended because showed the highest values of productivity and vegetation cover. The results indicated that the NDVI obtained through the GreenSeeker sensor can be used to estimate productivity, vegetation cover and plant population on peanut crop. This may provide an additional tool for farmers to evaluate the potential of their culture; enabling even that agronomic measures can take effect so that this potential is improved.
\end{abstract}

Keywords: Arachis hypogaea L., GreenSeeker, plant populations, terrestrial remote sensing.

Abbreviations: CV_coefficient of variation; DAE_days after emergence; LED_light emitting diodes; LSD_least significant difference; NDVI_normalized difference vegetation index; ns_not significant; PP_plant populations; $R^{2}$ _determination coefficient.

\section{Introduction}

Precision farming makes extensive use of geo-technologies, such as remote sensing, which obtains information on objects without physical contact, through the use of sensors. These systems are based on specific wavelengths that can be used, for example, to calculate the vegetation indices used to estimate production components of agricultural crops, among other applications. According to Villalba (2012), the determination of vegetation indices that express the potential for grain yield under different management systems is an important tool by which to identify the limiting factors and ideal crop management strategies. Jensen (2009) reported that by using vegetation indices it is possible to determine agronomic parameters, such as leaf area index, percentage of green cover, chlorophyll content, green biomass and others. The agronomic parameter Normalized Difference Vegetation Index (NDVI) was proposed by Rouse et al. (1974), which is a numeric indicator of the difference between the wavelengths of the red and near infrared bands divided by their sum. The NDVI shows good linear correlation with biomass compared to other vegetation indices, and it is also expected to be less influenced by changes in atmospheric conditions, moreover, it is a good indicator of vegetation biomass when the terrain exhibits good vegetation cover (Meneses et al., 2012), as is the case of the peanut crop whose shoots provide good cover. The NDVI is useful for obtaining yield information, such as photosynthetic efficiency and yield potential (Peñuelas et al., 1994; Raun et al., 2001; Báez-González et al., 2002). For example, studies by Grohs et al. (2009) and Povh et al. (2008) reported that grain yield may be related to the spectral reflectance of the vegetation, and this yield may be quantified through the NDVI (Raun et al., 2005). Based on this information, considering that the determination of the NDVI may be an alternative and indirect method for estimating the components of grain production and the fact that there is a lack of scientific data for the peanut crop, this study aimed to assess the relationship between agronomic variables of the peanut crop grown at different densities with the NDVI generated by the terrestrial sensor.

\section{Results}

\section{Analysis of variance}

The georeferenced map (Fig 1) shows the behavior of NDVI values in the experimental area, with values from 0.0 to 1.0 , varying 0.2 between them. The analysis of variance revealed a significant difference in the NDVI (Table 1) of population P1, which had the lowest value, to that of P4, which had the highest value. 
Table 1. Analysis of variance for the variables studied.

\begin{tabular}{|c|c|c|c|c|}
\hline \multirow{2}{*}{ Variables } & \multicolumn{4}{|c|}{ Population } \\
\hline & $P 1$ & $P 2$ & $P 3$ & P4 \\
\hline NDVI & $0.8675 c$ & $0.8785 b c$ & $0.8896 a b$ & $0.9003 a$ \\
\hline Yield $\left(\mathrm{kg} \mathrm{ha}^{-1}\right)$ & $3109.87 b$ & $3323.44 a b$ & $3537.01 a$ & $3644.25 a$ \\
\hline Mass of 100 grains $(\mathrm{g})$ & 49.04 & 48.72 & 48.39 & 50.32 \\
\hline Green mass $\left(\mathrm{kg} \mathrm{ha}^{-1}\right)$ & 28295 & 26750 & 25206 & 26297 \\
\hline Dry mass $\left(\mathrm{kg} \mathrm{ha}^{-1}\right)$ & 11287 & 10082 & 8878 & 9262 \\
\hline \multirow[t]{2}{*}{ Vegetation cover $(\%)$} & $93 b$ & $94 a b$ & $95 a$ & $95 a$ \\
\hline & $F$-test & $C V(\%)$ & $L S D$ & \\
\hline NDVI & $7.49 * *$ & 1.65 & 0.0203 & \\
\hline Yield $\left(\mathrm{kg} \mathrm{ha}^{-1}\right)$ & $4.83 *$ & 12.69 & 425.07 & \\
\hline Mass of 100 grains $(\mathrm{g})$ & $0.21^{\mathrm{ns}}$ & 10.54 & 7.21 & \\
\hline Green mass $\left(\mathrm{kg} \mathrm{ha}^{-1}\right)$ & $0.33^{\mathrm{ns}}$ & 23.69 & 8794.32 & \\
\hline Dry mass $\left(\mathrm{kg} \mathrm{ha}^{-1}\right)$ & $0.90^{\mathrm{ns}}$ & 32.14 & 4424.22 & \\
\hline Vegetation cover $(\%)$ & $4.92 * *$ & 1.58 & 2.06 & \\
\hline
\end{tabular}

141,144 plants ha ${ }^{-1}$, respectively). ns: not significant. *: significant $(\mathrm{P} \leq 0.05)$; **: significant $(\mathrm{P} \leq 0.01) \mathrm{CV}$ : coefficient of variation $(\%)$. LSD: least significant difference.

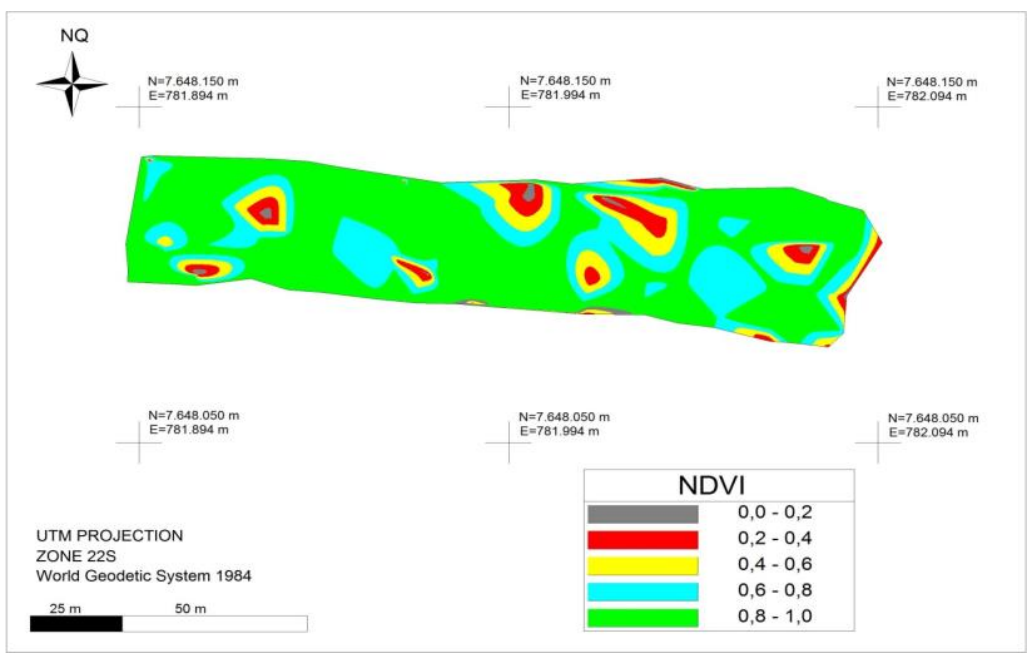

Fig 1. Georeferenced map of NDVI values in the sample area.

Table 2. Matrix of the Pearson correlation coefficients for the variables analyzed in relation to the NDVI.

\begin{tabular}{|c|c|c|}
\hline Variable & NDVI & Classification \\
\hline Yield $\left(\mathrm{kg} \mathrm{ha}^{-1}\right)$ & $0.7152 * *$ & Strong \\
\hline Mass of 100 grains $(\mathrm{g})$ & $0.5331 * *$ & Moderate \\
\hline Green Mass $\left(\mathrm{kg} \mathrm{ha}^{-1}\right)$ & $0.5623^{* *}$ & Moderate \\
\hline Dry Mass $\left(\mathrm{kg} \mathrm{ha}^{-1}\right)$ & $0.5255^{* *}$ & Moderate \\
\hline Vegetation cover $(\%)$ & $0.8419 * *$ & Strong \\
\hline Plant populations & $0.6819 * *$ & Strong \\
\hline
\end{tabular}

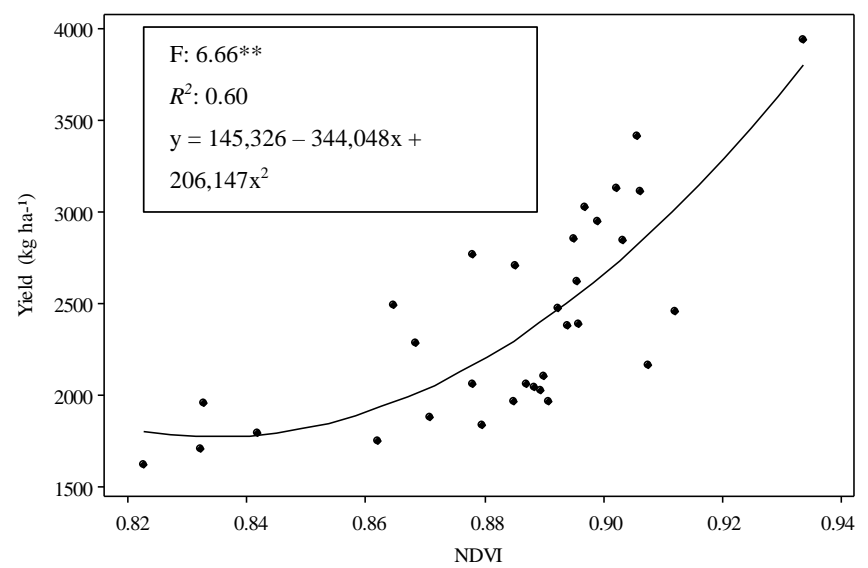

Fig 2. Regression analysis between yield and NDVI in the peanut crop. **significant at $1 \%$ probability. $R^{2}$ : coefficient of determination. 
Table 3. Correlation coefficient intervals and interpretation.

\begin{tabular}{ll}
\hline Interval & Interpretation \\
\hline $0.00-0.30$ & Weak correlation \\
$0.30-0.60$ & Moderate correlation \\
$0.60-0.90$ & Strong correlation \\
$0.90-1.00$ & Very strong correlation \\
\hline
\end{tabular}

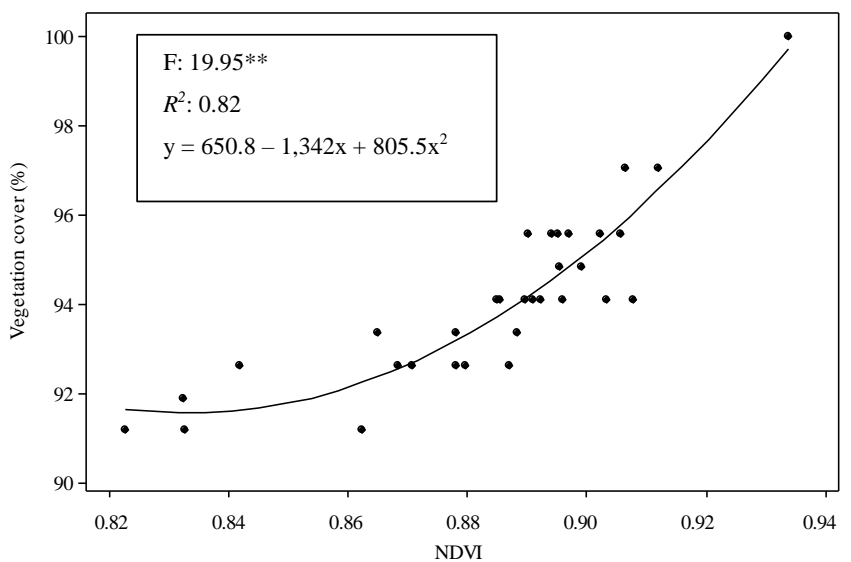

Fig 3. Regression analysis between vegetation cover and the NDVI of the peanut crop. **significant at $1 \%$ probability. $R^{2}$ : coefficient of determination.

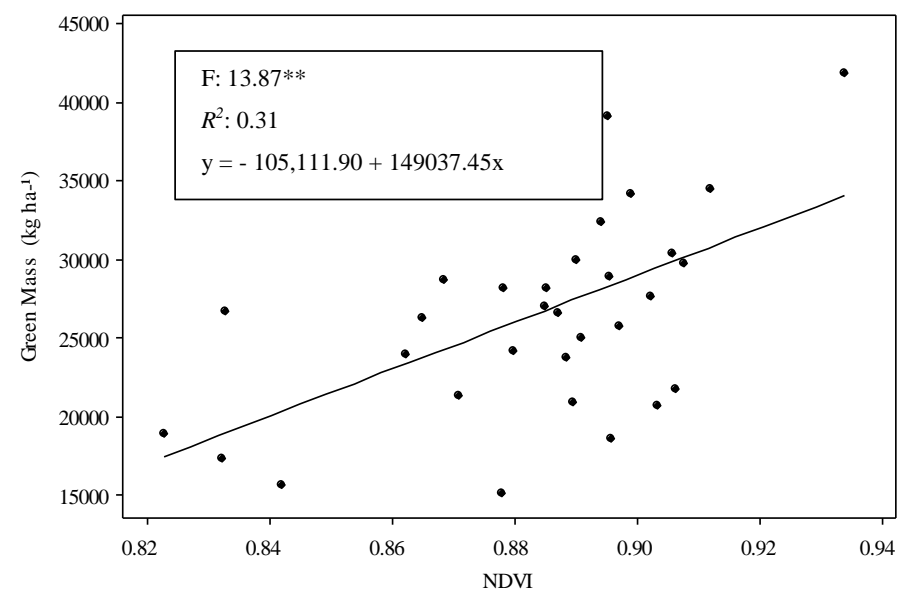

Fig 4. Regression analysis between green mass and the NDVI of the peanut crop. ${ }^{* *}$ significant at $1 \%$ probability. $R^{2}$ : coefficient of determination.

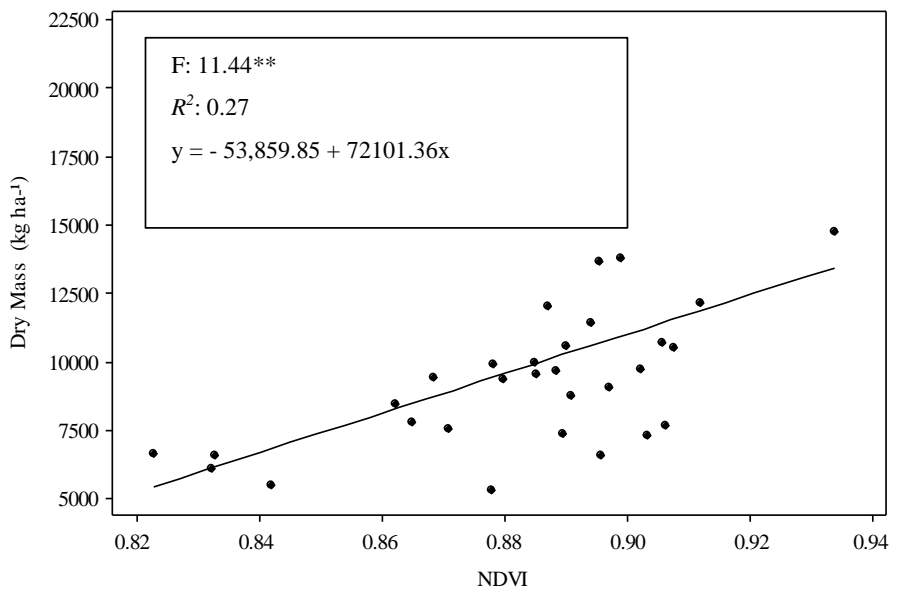

Fig 5. Regression analysis between the dry mass and the NDVI of the peanut crop. **significant at $1 \%$ probability. $R^{2}$ : coefficient of determination. 


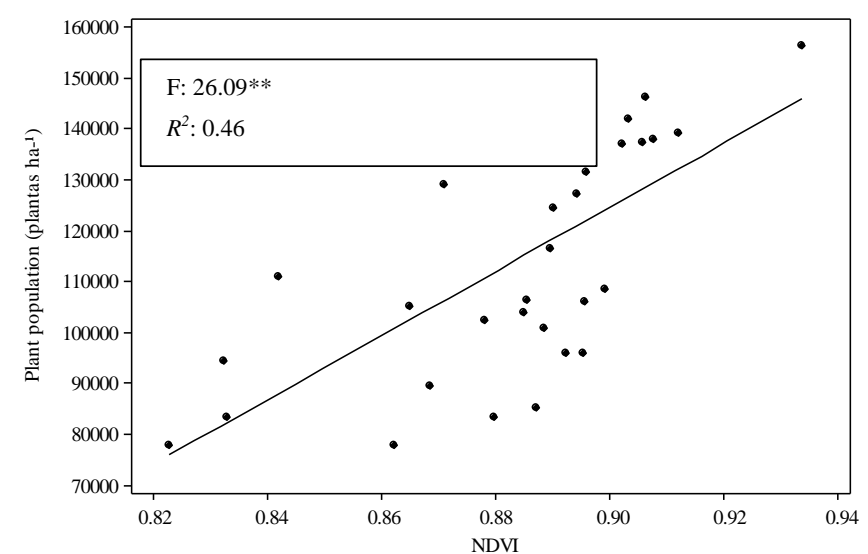

Fig 6. Regression analysis between plant populations and the NDVI of the peanut crop. **significant at $1 \%$ probability. $R^{2}$ : coefficient of determination.

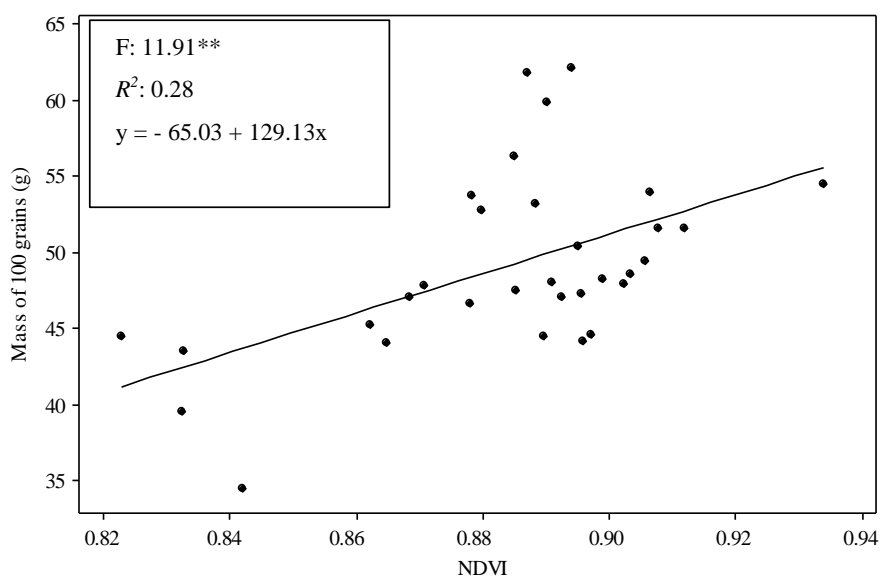

Fig 7. Regression analysis between the mass of 100 grains and the NDVI of the peanut crop. **significant at $1 \%$ probability. $R^{2}$ : coefficient of determination.

In the densest plant populations, there were fewer gaps among the plant shoots, which results in higher NDVI values. Thus, it is possible to establish relationships between the NDVI and other agronomic characteristics that have similar behavior, such as yield and vegetation cover. The two densest plant populations ( $\mathrm{P} 3$ and $\mathrm{P} 4$ ) resulted in higher yields, and the lowest population (P1) had the lowest yield, while P2 did not differ from the others (Table 1). This result may be due to population P1 containing an insufficient number of plants to achieve high yields. In P4, the increased plant population may have resulted in competition for space, water and nutrients from the soil. Thus, in plant populations of intermediate density, there may have been compensatory production by the plants, reaching a final yield equal to that of the more dense populations. There was no difference in the weight of 100 grains among treatments (Table 1). A possible reason for this result is that the size and mass of grains produced by peanut plants is a genetic characteristic of the cultivar; therefore, the density at which the plants are grown does not matter. Neither the green mass nor the dry mass differed among the densities evaluated (Table 1). In denser populations, there is competition for light between plants, and this competition arrests shoot development at a certain point of growth. For less dense plant populations, there is space for further development of shoots. Therefore, because of their creeping nature, the plants spread and produce more plant material.

There was a significant difference in vegetation cover between the densities (Table 1), where populations P3 and P4 had higher values compared to P1. The least dense population (P1) had fewer shoots for total ground cover compared to the other plant populations. However, there was no significant difference between P2, P3 and P4, demonstrating the compensatory effect of shoot growth when moving from a more dense to a less dense population.

\section{Regression analysis}

The regression analysis indicated that there was a quadratic positive significance of the NDVI versus yield (Fig 2), resulting in a correlation of determination of 0.60 . In the phenological growth stage studied, when the crop is fully developed, there may be homogeneity of reflectance, saturating the NDVI. In this case, the analysis of variance indicated that the two denser plant populations did not differ in yield, vegetation cover or the NDVI itself. Vegetation cover by the peanut plants (Fig 3) followed the same pattern obtained for the yield with concave positive quadratic regression but with the highest determination coefficient $\left(R^{2}=\right.$ 0.82 ); the minimum NDVI point was 0.83 , a value very close to that found for yield. The analysis of variance confirmed the similarities between the two densest populations, showing the compensatory effect of shoot production. In less dense populations, shoot production per plant is maximized; when plant density increases, production decreases, although the individual decrease is offset by an increase in the number of 
individuals per area (Mercante et al., 2009). Thus, this factor may limit the perception of changes in the NDVI when there is variation in a plant population that does not reach the level for the populations analyzed in this study.

When comparing the NDVI with the green and dry masses (Fig 4 and 5), the values of the coefficient of determination were lower, 0.31 and 0.27 , respectively, indicating a significant positive linear regression. Because the grain yield partially depends on the dry mass, it was expected that the same behavior would occur for dry mass and yield.

In the previously cited works for diverse crops, the coefficients of determination were high; thus, there is potential for the use of the NDVI in estimating the dry mass yield. Therefore, in the present study for the peanut crop in the phenological stage (maturation of pods), this effect was not observed. The coefficient of determination of the linear regression for the plant populations (Fig 6) was average (0.46). This fact may be explained, according to Merchant et al. (2009), by the fact that for peanuts and soybeans, low coefficient of determination values may occur due to the indeterminate growth habit and high capacity to compensate for flaws by the production of lateral branches (creeping scale). Thus, this factor may limit the perception of changes in the NDVI when there is variation in plant density.

Green vegetation has strong absorption in the red region of the spectrum (approximately $670 \mathrm{~nm}$ ); reflectance in this range is low (3 to 5\%). In the near infrared region, vegetation has high reflection of the incident radiation, reaching between 40 and 60\% Increases in crop biomass also increase reflectance in the near infrared range. Additionally, the normalization process makes the NDVI insensitive to variations in reflectance in the near infrared range when this variation is much higher than that in the red range (Gitelson, 2004).

Regarding the mass of 100 grains (Fig 7), the linear regression fit relative to the NDVI was noted, although the coefficient of determination was not significant $\left(\mathrm{R}^{2}=0.28\right)$.

The lack of a difference in the analysis of variance proves once again that the grain mass is an intrinsic characteristic of the cultivar, as discussed in the analysis of variance, which is reflected in the low correlation with the vegetation index.

The correlation analysis showed that the correlation coefficients between the variables with respect to the NDVI were significant and positive (Table 2). According to Callegari-Jacques (2003), the correlation coefficient (R) may be qualitatively evaluated according to the criteria of Table 3 . The variables vegetation cover, yield and plant population showed strong correlations with the NDVI, and the other agronomic variables, green mass, dry mass and mass of 100 grains, moderately correlated with the NDVI obtained by the terrestrial sensor.

\section{Discussion}

According to Brown et al. (2005), the final population of peanut plants is one factor among several production characteristics that can influence yield. For the 100-grain weight, according to Oliveira et al. (2010), when working with the cultivar Runner IAC 886, also observed no significant variations in grain size between peanut cultivars and among spacing used, with an overall average 100-grain weight of $41.17 \mathrm{~g}$. Thus, there is no correlation between the NDVI and the 100-grain weight. For domestic fresh consumption, the average grain mass is well established because several commercial cultivars have a 100-grain mass similar to that obtained for the cultivar Runner IAC 886 (Godoy et al., 2005). Crusciol and Soratto (2007) found a 100-grain mass of $35.3 \mathrm{~g}$ for the cultivar IAC Tatu Vermelho, when spaced at $0.45 \mathrm{~m}$ between rows and grown at 18 seeds $\mathrm{m}^{-1}$ in each row. Nakagawa et al. (1994) used the same cultivar and found no difference in the weight of 100 grains between plants grown at different densities, which ranged from 7 to 28 seeds $\mathrm{m}^{-1}$ and varied by intervals of three.

In the case of NDVI, according to Ma et al. (2001), there is a positive correlation between reflectance of the crop canopy, expressed in NDVI values, and crop yield. In remote sensing, the use of exponential functions is common to express the relationship between the indicator variable and the NDVI (Liu, 2006). Myneni et al. (2002) analyzed the NDVI for different canopies and found that saturation does not allow for differentiation of areas that characterize the variation of the canopy and that may be correlated with yield. Similar analyses generated with the NDVI readings from diverse cultures and locations have been used by various authors to estimate crop yield (Raun et al., 2001; Freeman et al., 2003; Moges et al., 2004; Inman et al., 2005). The main disadvantage of the NDVI is the non-linear relationship with biophysical characteristics such as biomass and leaf area index (Myneni et al., 1995). Generally, the NDVI reaches saturation at medium to high quantities of biomass and for certain leaf area indices (Gitelson et al., 2002), but this effect tends to be more proportional to biomass compared to other existing vegetation indices (Meneses et al., 2012). Santos Júnior et al. (2001) observed a relationship between mass and the NDVI in soybeans. However, Epstein et al. (2005) used satellite imagery to measure the NDVI and its relationship with the yield of grasses and found a higher coefficient of determination (0.60) than that obtained in the present study. Lamb et al. (2009) evaluated the mass of sorghum (Sorghum bicolor) using the active sensor Crop Circle $₫$ and obtained a correlation coefficient of 0.90 . Hancock and Dougherty (2007), evaluating the NDVI in alfalfa and its relationship to dry mass, found a coefficient of determination of 0.58 . Phillips et al. (2004) used the NDVI values to estimate the density of wheat plants and obtained a coefficient of determination of 0.74 ; this correlation was achieved only by the population of 1,000 plants $\mathrm{m}^{-2}$, and at higher densities, the NDVI was not considered an estimator of density. Ma et al. (2001) studied three soybean plant densities in two soil textures (sandy and clayey) in two consecutive years and concluded that plant density is not related to the NDVI. Ahmadi and Mollazade (2009), evaluating the NDVI obtained from satellite imagery, found good correlation for soybean plant density (coefficient of determination $=0.87$ ). Merchant et al. (2010), when working with the soybean crop and evaluating the NDVI calculated from satellite images to estimate the yield, encountered a similar average correlation as that in the present study with a value of 0.69. Similarly, Boechat (2012) found significant and positive correlations of 0.56 and 0.48 between the NDVI and the yield of the common bean at 59 and 90 days after emergence (DAE), respectively (data obtained by the spectroradiometer). The same author, in another experiment on calibrated data from digital images, obtained correlations of 0.63 and 0.79 between yield and NDVI at 28 and 42 DAE for the common bean, respectively.

The explanation for the good correlation between measures of reflectance and yield, according to Silva et al. (2009), is that the yield is related to the amount of radiation intercepted by the crop, and reflectance correlates with the amount of photosynthetically active leaf tissue present per unit area capable of intercepting solar radiation. 


\section{Materials and Methods}

\section{Experimental area}

The experiment was conducted at the Teaching, Research and Production Farm, UNESP/Jaboticabal-SP, near $21^{\circ} 14^{\prime}$ 'S latitude and $48^{\circ} 17^{\prime} \mathrm{W}$ longitude, with an altitude and average slope of 560 meters and 4\%, respectively. The soil in the experimental area was classified as Eutroferric RED LATOSOL (oxisol), with clay-like texture and mild undulating relief, according Andrioli and Centurion (1999).

According to the Köppen classification, the climate is Aw, defined as tropical humid with a rainy season in the summer and a dry season in the winter, with an average annual temperature of approximately $22^{\circ} \mathrm{C}$. The rainfall for this region during the experiment was $705 \mathrm{~mm}$, and the average temperature was $23.8{ }^{\circ} \mathrm{C}$, measured by an on-site weather station.

\section{Plant materials and treatments}

The peanut (Arachis hypogaea L.) cultivar Runner IAC 886 was sown in soil with conventional tillage, subjected to heavy tilling to a depth of $0.20 \mathrm{~m}$ and two light tillings, both using disc harrows. Prior to soil preparation, sub soiling was performed to a depth of $0.40 \mathrm{~m}$ to break up compacted layers at $0.35 \mathrm{~m}$ of depth. The seeds were treated with the active ingredient thiamethoxam at a dose of $1 \mathrm{~g} \mathrm{~kg}^{-1}$ and exhibited germination percentages of $85 \%$ in the laboratory, as determined at the Seed Analysis Laboratory, UNESP/Jaboticabal.

Peanuts were sown mechanically with row spacing of 0.90 $\mathrm{m}$ at the population densities of $10,12,14$ and 18 seeds $\mathrm{m}^{-1}$, corresponding to $86,111,103,520,127,603$ and 141,144 plants ha ${ }^{-1}$, and these treatments were identified as P1, P2, P3 and $\mathrm{P} 4$, respectively. These populations were evaluated in a randomized block design with 6 replicates, thus totaling 24 experimental plots that measured $240 \mathrm{~m}^{2}$; three passes per plot were made by the tractor-planter, which had four rows spaced at $0.90 \mathrm{~m}$.

\section{Variables measured}

A commercially utilized device available for determining the NDVI at the ground level is the GreenSeeker. This device emits electromagnetic radiation through two types of LED (light emitting diodes) in the red $(650 \mathrm{~nm})$ and near infrared $(770 \mathrm{~nm})$ electromagnetic spectrum ranges toward the crop, which absorbs and reflects part of this radiation. Reflectance is captured by optical sensors and processed internally to calculate the NDVI (Cortinove et al., 2012).

Sensory evaluation with the GreenSeeker device was performed manually by passing the device over the top of the plant at a height of approximately $0.50 \mathrm{~m}$, always evaluating the four center rows of each plot. Data were collected when the crop was fully developed, approximately 100 days after sowing (phase of maturation of pods). Sensory data were processed with the FarmWorks software and in a spreadsheet. Samples of sensing with GreenSeeker were georeferenced with "Trimble Nomad 800 Series GPS receiver".

The agronomic variables analyzed were vegetation cover of the soil by shoots of the peanut, green mass and dry mass of the shoots, pod yield and weight of 100 grains. The percentage of ground cover was determined in all experimental plots at 100 days after sowing using a nylon cord marked with 50 points spaced every $10 \mathrm{~cm}$, according to the methodology adapted from Laflen et al. (1981).

The mass of green matter of the peanut plants was determined after manual harvest. The shoots found within a $2.00 \mathrm{~m}^{2}$ metal frame were collected and randomly distributed into each plot, and subsamples were removed and dried at $70^{\circ} \mathrm{C}$ for 48 hours. The dry masses of the shoots were also determined.

The actual yield was determined according to Silva and Mahl (2008) by uprooting all peanut plants contained in the 2 $\mathrm{m}^{2}$ area of the metal frame and collecting the pods that were above and below the soil surface to an approximate depth of 0.15 meters. The pods were sieved and placed in paper bags to subsequently weigh them and obtain the yield. The water content of all samples was adjusted to $8 \%$ (water content for peanut storage), and subsequently, the values were converted to $\mathrm{kg} \mathrm{ha}^{-1}$.

The weight of 100 grains was determined by separating the grains from the pods for each plot, whose masses were determined on an electronic scale accurate to $0.01 \mathrm{~g}$; these procedures were conducted according to the guidelines established by the Rules of Seed Analysis (Brasil, 2009).

\section{Statistical analysis}

To analyze the data, the assessment of normality was performed by the Anderson-Darling test; when asymmetric, the data were transformed to achieve normality by means of the equation y' $=1 / \sqrt{ } \mathrm{y}$. Subsequently, an analysis of variance (ANOVA) was performed, applying the Snedecor F test with a significance level of 5\%, to determine whether there were significant differences between the means of the variables analyzed. When appropriate, Tukey's test was applied at 5\% probability. Analyses of regression and correlation for the significant effects were also performed, and the coefficients of the components of each model were tested to then select the significant models with higher coefficients of determination and correlation. All statistical data analysis was done in software Minitab 16®.

\section{Conclusions}

The variables vegetation cover, yield and peanut plant population showed strong correlations with the NDVI obtained by the terrestrial sensor. The two densest peanut plant populations showed similar behavior of the variables analyzed. The results indicated that the Vegetation Index Normalized Difference - NDVI obtained through the GreenSeeker sensor can be used to estimate productivity, vegetation cover and plant population on peanut crop. This may provide an additional tool for farmers to evaluate the potential of their culture; enabling even that agronomic measures can take effect so that this potential is improved. With respect to seeding rates, the higher densities (14 and 18 seeds $\mathrm{m}^{-1}$ ) are the most recommended because showed the highest values of productivity and vegetation cover.

\section{Acknowledgments}

The authors thank the National Council for Scientific and Technological Development and Coordination of Improvement of Higher Education Personnel, by grants granted to authors. 


\section{References}

Ahmadi H, Mollazade K (2009) Determination of soya plant population using NDVI in the dasht e naz agriindustry. J Agr Sci. 1:112-120.

Andrioli I, Centurion JF (1999) Detailed survey of the soils of the Jaboticabal Faculty of Agricultural Scienses and Veterinary. Paper presented at the XXVII Brazilian Congress of Soil Science, Brazilian Society of Soil Science, Brasília, 1116 July 1999.

Báez-González AD, Chen P, Tiscareno-Lopez M, Srinivasan R (2002) Using satellite and field data with crop growth modelling to monitor and estimate corn yield in Mexico. Crop Sci. 42:1943-1949.

Boechat LT (2012) Remote sensing techniques for the detection of white mold and angular leaf spot in the common bean. Thesis (Doctorate in Agricultural Engineering), Viçosa, MG: Universidade Federal de Viçosa, pp 128.

Brasil, Ministério da Agricultura, Pecuária e Abastecimento. Secretaria de Defesa Agropecuária (2009) Rules for seed analysis, Brasília: Ministério da Agricultura, Pecuária e Abastecimento, pp 398.

Brown SL, Culbreath AK, Todd JW, Gorbet DW, Baldwin JA, Beasley JP (2005) Development of a method of risk assessment to facilitate integrated management of spotted wilt of peanut. Plant Dis. 89:348-356.

Callegari-Jacques SM (2003) Biostatistics: principles and applications. Porto Alegre: Artemed, pp.196.

Cortinove L, Taubinger L, Amaral LR, Molin JP (2012) Density of data collection with an active optical sensor for nitrogen fertilization in sugarcane, corn and wheat. Paper presented at the Brazilian Congress of Precision Agriculture, Ribeirão Preto - SP, 24-26 september 2012.

Crusciol CAC, Soratto RP (2007) Peanut crop nutrition and yield in a no-tillage system in succession to cover crop growth. Pesqui Agropecu Bras. 42:1553-1560.

Epstein HE, Walker DA, Jia GJ, Kelley AM (2005) Climate, plant biomass, NDVI and LAI relationships along the full arctic bioclimate gradient. Am Geophys Union. 23:1012-1024.

Freeman KW, Raun WR, Johnson GV, Mullen RW, Stone ML, Solie JB (2003) Late-season prediction of wheat grain yield and grain protein. Commun Soil Sci Plan. 34:1837-1852.

Gitelson AA, Kaufman Y J, Stark R, Rundquist D (2002) Novel algorithms for remote estimation of vegetation fraction. Remote Sens Environ. 80:76-87.

Gitelson AA (2004) Wide dynamic range vegetation index for remote quantification of biophysical characteristics of vegetation. J Plant Physiol. 161:165-173.

Godoy IJ, Minotti D, Resende PL (2005) High quality peanut production. Viçosa: CPT, pp 168.

Grohs DS, Bredemeier C, Mundstock CM, Poletto N (2009) Model for yield potential estimation in wheat and barley using the GreenSeeker sensor. Eng Agric. 29:101-112.

Hancock DW, Dougherty CT (2007) Relationships between blue- and red-based vegetation indices and leaf area and yield of alfalfa. Crop Sci. 47:2547-2556.

Inman D, Khosla R, Mayfield T (2005) On-the-go active remote sensing for efficient crop nitrogen management. Sensor Rev. 25:209-214

Jensen JR (2009) Remote sensing of the environment: a perspective on terrestrial resources. 2nd ed. São José dos Campos: Parêntese, pp 604.

Laflen JM, Amemiya A, Hintz EA (1981) Measuring crop residue cover. J Soil Water Conserv. 36:341-343.

Lamb DW, Trotter MG, Schneider DA (2009) Measuring and mapping crop vigour using an active optical sensor in an ultralow level aircraft. Paper presented at the Symposium on precision agriculture in Australia, Amidale, 2009.

Liu WTH (2006) Applications of remote sensing. Campo Grande: UNIDERP, pp 908.
Ma BL, Dwyer LM, Costa C, Cober ER, Morrison MJ (2001) Early prediction of soybean yield from canopy reflectance measurements. Agron J. 93:1227-1234.

Meneses PR, Almeida T, Rosa ANCS, Sano EE, Souza EB, Baptista GMM, Brites RS (2012) Introduction to processing of remote sensing images. Brasília: UnB, pp 266.

Mercante E, Lamparelli RAC, Uribeopazo MA, Rocha JV (2009) Spectral characteristics of soybean during the vegetative cycle with landsat 5/TM images in the western Paraná, Brazil. Eng Agric. 29:328-338.

Moges SM, Raun WR, Mullen RW, Freeman KW, Johnson GV, Solie JB (2004) Evaluation of green, red, and near infrared bands for predicting winter wheat biomass, nitrogen uptake, and final grain yield. J Plant Nutr. 27:1431-1441.

Myneni RB, Hall FG, Sellers PJ, Marshak AL (1995) The interpretation of spectral vegetation indexes. T Geos Remote Sens. 33:481-486.

Myneni RB, Knyazikhin Y, Privette JL, Glassy J, Tian Y, Wang Y, Song X, Zhang Y, Smith GR, Lotsch A, Friedl M, Morisette JT, Votava P, Nemani RR, Running SW (2002) Global products of vegetation leaf area and fraction absorbed PAR from year one of MODIS data. Remote Sens Environ. 28:214231.

Nakagawa J, Lasca DC, Neves JPS, Neves GS, Sanches SV, Barbosa V, Silva MN, Rosseto CAV (1994). Effect of planting density on peanut production. Pesqui Agropecu Bras. 29:15471555.

Oliveira TMM, Queiroga RCF, Nogueira FP, Moreira JN, Santos MA (2010) Production decumbent peanut cultivars subjected to different spacings. Rev Caat. 23:149-154.

Peñuelas J, Gamon JA, Fredeen AL, Merino J, Field CB (1994) Reflectance indices associated with physiological changes in nitrogen- and water-limited sunflower leaves. Remote Sens Environ. 48:135-146.

Phillips SB, Keahey DA, Warren JG, Mullins GL (2004) Estimating winter wheat tiller density using spectral reflectance sensors for early-spring, variable-rate nitrogen applications. Agron J. 96:591-600.

Povh FP, Molin JP, Gimenez LM, Pauletti V, Molin R, Salvi JV (2008) Behavior of NDVI obtained from an active optical sensor in cereals. Pesqui Agropecu Bras. 23:1075-1083.

Raun WR, Solie JB, Johnson GV, Stone ML, Ukina EV, Thomason WE, Schepers JS (2001). In-season prediction of potential grain yield in winter wheat using canopy reflectance. Agron J. 93:131-138.

Raun WR, Solie JB, Stone ML, Martin KL, Freeman KW, Mullen RW, Zhang H, Schepers JS, Johnson GV (2005) Optical sensor-based algorithm for crop nitrogen fertilization. Commun Soil Sci Plan, 36:2759-2781.

Rouse JW, Haas RH, Schell JA, Deering DW, Harlan JC (1974) Monitoring the vernal advancement and retrogradation (greenwave effect) of natural vegetation. NASA/GSFC Type III Final Report. Greenbelt, MD, pp 371.

Santos Júnior RF, Santos JM, Rudorff BFT, Marchiorato IA (2001) Field in the visible and near infrared range for the detection of areas infested with Meloidogyne javanica in soybean. Paper presented at the Congresso Brasileiro de Nematologia, Marília, 2001.

Silva AJ, Canteri MG, Santiago DC, Hikishima M, Silva AL (2009) The reflectance in the estimate of the effect of fungicides in the control of Asian soybean rust. Sum Phytopathol. 35:53-56.

Silva RP, Mahl D (2008) Report of the research project: Losses in mechanical harvesting peanut crop 2007/2008. Research Report. Laboratory of Machinery and Agricultural Mechanization - LAMMA, pp 47.

Villalba EOH (2012) Nutritional status of corn evaluated by optical spectroscopy in Paraguay. Thesis (Doctorate in Agricultural Engineering). Universidade Federal de Santa Maria, pp 132. 